\title{
Radiologic features of precancerous areas of the lungs in chronic obstructive pulmonary disease
}

\author{
This article was published in the following Dove Press journal: \\ International Journal of COPD \\ 30 May 2017 \\ Number of times this article has been viewed
}

\author{
Shotaro Chubachi' \\ Saeko Takahashi' \\ Akihiro Tsutsumi ${ }^{\prime}$ \\ Naofumi Kameyama' \\ Mamoru Sasaki ${ }^{1}$ \\ Katsuhiko Naoki' \\ Kenzo Soejima' \\ Hidetoshi Nakamura ${ }^{2}$ \\ Koichiro Asano 3 \\ Tomoko Betsuyaku' \\ On behalf of the Keio \\ COPD Comorbidity \\ Research Group \\ 'Division of Pulmonary Medicine, \\ Department of Medicine, Keio \\ University School of Medicine, \\ Shinjuku-ku, Tokyo, ${ }^{2}$ Department \\ of Respiratory Medicine, Saitama \\ Medical University, Irima-gun, \\ Saitama, ${ }^{3}$ Division of Pulmonary \\ Medicine, Department of Medicine, \\ Tokai University School of Medicine, \\ Isehara-shi, Kanagawa, Japan
}

\begin{abstract}
Background: Only a few studies have evaluated the radiologic features of pre-existing structural abnormalities where lung cancer may develop. This study aimed to analyze the computed tomography (CT) images of lung areas where new cancer developed in chronic obstructive pulmonary disease (COPD) patients.

Patients and methods: We conducted a multicenter, longitudinal cohort study, called the Keio COPD Comorbidity Research, to assess the incidence of lung cancer. Emphysema and interstitial abnormalities were evaluated in 240 COPD patients who had baseline CT scans applicable for further digital analyses. For patients who developed lung cancer during the 3-year follow-up period, the local spherical lung density of the precancerous area was individually quantified.

Results: Lung cancer was newly diagnosed in 21 participants (2.3\% per year). The percentage of low attenuation area in patients who developed lung cancer was higher than that of the other patients $(20.0 \%$ vs $10.4 \%, P=0.014)$. The presence of emphysema (odds ratio [OR] 4.2 , $95 \%$ confidence interval $[\mathrm{CI}] 1.0-29.0, P=0.049$ ) or interstitial lung abnormalities (OR 15.6, 95\% CI 4.4-65.4, $P<0.0001)$ independently increased the risk for lung cancer. Compared with the density of the entire lung, the local density of the precancerous area was almost the same in patients with heterogeneous emphysema, but it was higher in most patients with interstitial abnormalities.
\end{abstract}

Conclusion: The presence of emphysema or interstitial abnormalities or a combination of both were independent predictors of lung cancer development in COPD patients. Furthermore, lung cancer most often developed in non-emphysematous areas or in interstitial abnormalities.

Keywords: COPD, lung cancer, emphysema, interstitial lung disease, computed tomography

\section{Introduction}

The incidence of malignant tumors in patients with COPD was estimated to be $6 \%-18 \%{ }^{1}$ Lung cancer is thought to be an important complication that accounts for $5 \%-38 \%$ of COPD deaths. ${ }^{2}$ It is a well-known fact that the risk for lung cancer increases with the duration of smoking or secondhand smoke exposure. ${ }^{3}$ In addition, the frequency of lung cancer is higher in smokers with COPD than in those without COPD ${ }^{4,5}$ and COPD itself is an independent risk factor for lung cancer. One study reported that the risk for lung cancer rises with the progression of airflow limitation in COPD. ${ }^{6}$ On the other hand, a recent report stated that patients with mild stage of COPD were at a higher risk for lung cancer than those with moderate or severe COPD. ${ }^{7}$ So far, the risk for lung cancer according to the severity of airflow limitation has been controversial. On the other hand, some studies showed that pulmonary emphysema was a risk factor for lung cancer, independent of smoking history and airflow limitation. ${ }^{7-9}$ In a COPD lung, the pattern and distribution of emphysematous changes are heterogeneous; interstitial and bullous changes are likewise often observed..$^{10,11}$
Correspondence: Tomoko Betsuyaku Division of Pulmonary Medicine, Department of Medicine, Keio University School of Medicine, 35 Shinanomachi, Shinjuku-ku, Tokyo 160-8582, Japan

Tel $+8 \mid 353633406$

Fax +8I 333532502

Email tbetsuyaku@z5.keio.jp
International Journal of COPD 2017:12 1613-1624

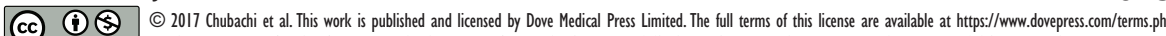

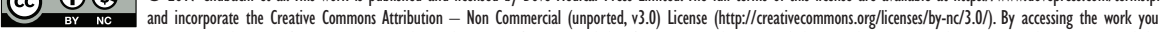
hereby accept the Terms. Non-commercial uses of the work are permitted without any further permission from Dove Medical Press Limited, provided the work is properly attributed. For permission for commercial use of this work, please see paragraphs 4.2 and 5 of our Terms (https://www.dovepress.com/terms.php). 
There have been studies on the coexistence of COPD among patients with lung cancer. ${ }^{12,13}$ Some studies have investigated the changes on computed tomography (CT) scans surrounding lung cancer as "background" lung structure. However, this result may be misleading because various secondary changes can be due to the development of cancer. ${ }^{14,15}$ Therefore, the structure of the lungs before the development of lung cancer was not always reflected. To date, few studies have retrospectively investigated the preexisting structural abnormalities of the lungs before cancer developed. ${ }^{16}$

In this study, we aimed to explore the individual association of quantitative measures of emphysema and visual analysis of interstitial abnormalities on CT scan with changes in the entire lung with cancer. Furthermore, we quantitatively measured the local CT densities of the precancerous sites and assessed if these may be candidate variables for future risk models.

\section{Patients and methods}

\section{Study population}

The overall design of the Keio COPD Comorbidity Research (K-CCR) has been previously published. ${ }^{17-19}$ This study was a 3-year, prospective, observational study that enrolled 572 men and women, aged 40-91 years, who had been diagnosed by pulmonary physicians with COPD and at risk for COPD from April 2010 to December 2012. For this study, we selected and analyzed data from COPD patients without any suspicious lung cancer findings at baseline CT $(n=435)$. Written informed consent to analyze and present their data was obtained from each patient, and the study (University Hospital Medical Information Network; UMIN000003470) was approved by the ethics committees of Keio University and its affiliated hospitals (20090008). The study conforms in all respects to the Declaration of Helsinki adopted by the 59th WMA General Assembly, Seoul, Korea, October 2008.

\section{Assessment of clinical parameters}

At enrollment and annually, full medical history and smoking history, as well as information about the current pharmacologic treatment, were obtained. ${ }^{20}$ Spirometry was performed in all patients under stable conditions using an electronic spirometer (CHESTAC-9800; CHEST, Tokyo, Japan) according to the guidelines of the American Thoracic Society. ${ }^{21}$ Predicted values of spirometric measurements were derived from the guidelines of the Japanese Respiratory Society. ${ }^{22}$ For quantitative and qualitative analyses of emphysema and interstitial abnormalities, only 240 COPD patients had baseline high-resolution CT scans that were applicable for further digital analyses. CT examination was performed using five multi-detector CT scanner: 64-detector CT (LightSpeed VCT and Discovery CT 750 HD; General Electric Medical Systems, Milwaukee, WI, USA, or Aquilion 64; Toshiba Medical Systems, Otawara, Japan), 256-detector CT (Revolution CT; General Electric Medical Systems), or 320-detector CT (Aquilion One Genesis; Toshiba Medical Systems). All subjects underwent volumetric CT at full inspiration and at the end of a normal expiration. Scanning parameters for each scanner were as follows: the detector collimation was $0.5-0.625 \mathrm{~mm}$; beam pitch, 0.813-0.984; reconstruction thickness, $1.0-1.25 \mathrm{~mm}$; reconstruction interval, $1.0-1.5 \mathrm{~mm}$; rotation time, $0.35-0.5$ seconds; tube voltage, $120 \mathrm{kVp}$; tube current, Auto mAs (standard deviation $[\mathrm{SD}]=12-15)$; and reconstruction kernel, chest for GE machine or FC 50 for Toshiba machine. For calibration among five CT scanners, a test object (Multipurpose Chest Phantom N1; Kyoto Kagaku, Kyoto, Japan) was scanned at the start of the study using each scanner. ${ }^{23}$

\section{Assessment of emphysema}

The extent of emphysema was quantified as the ratio (\%) of low attenuation area to total lung volume (low attenuation area [LAA]\%) with Hounsfield units of less than -950 (AZE Ltd., Tokyo, Japan), as previously reported ${ }^{23}$ The presence of emphysema was defined as LAA $\% \geq 10 \%$ and was classified as mild $(\geq 10 \%-<20 \%)$ or moderate/severe $(\geq 20 \%){ }^{23}$

\section{Assessment of interstitial abnormalities}

$\mathrm{CT}$ findings were sequentially read by four pulmonologists and were scored as follows: type $0=$ no evidence of interstitial lung disease (ILD), type $1=$ equivocal for ILD, type $2=$ suspicious for ILD, and type $3=$ ILD. Interstitial abnormalities were registered as either absent $(0+1)$ or present $(2+3) .{ }^{11,24}$ In the sequential reading process, the $240 \mathrm{CT}$ scans were divided among four picture archiving and communication system workstations. Reader 1 or 2 would review the scans at his or her station and provide a corresponding score. CT scans that were scored as types 1,2, and 3 were provided to reader 3, who was blinded to the initial interpretation. Finally, reader 4 , who was blinded to the interpretations of readers 1 , 2 and 3 , contributed to majority opinion on scans that were discordantly scored by the three readers.

\section{Quantification of local lung density}

A $2 \mathrm{~cm}$ diameter sphere was arbitrarily created in the site where lung cancer would develop later on three-dimensional (3D) image of CT, and the local spherical lung density of the sphere was measured (AZE Ltd., Tokyo, Japan). The $2 \mathrm{~cm}$ 
A

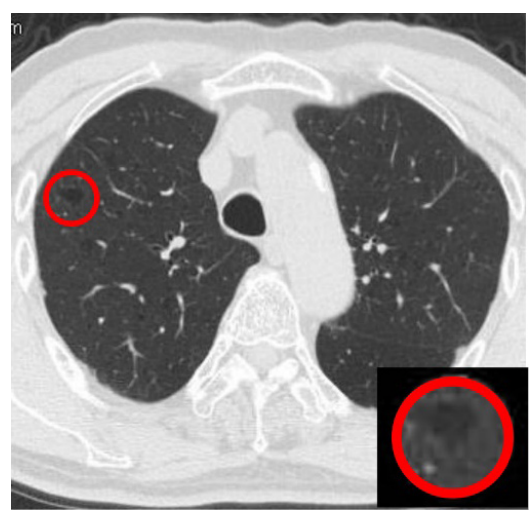

C

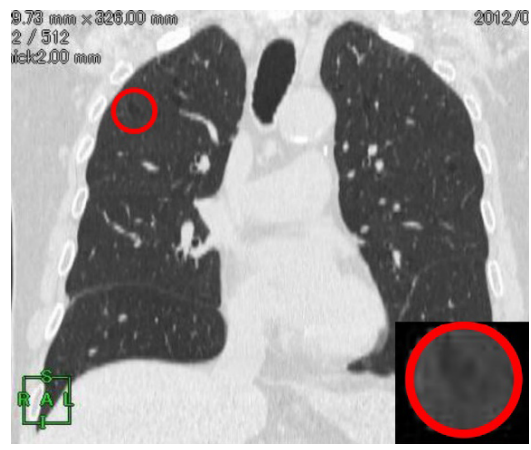

B

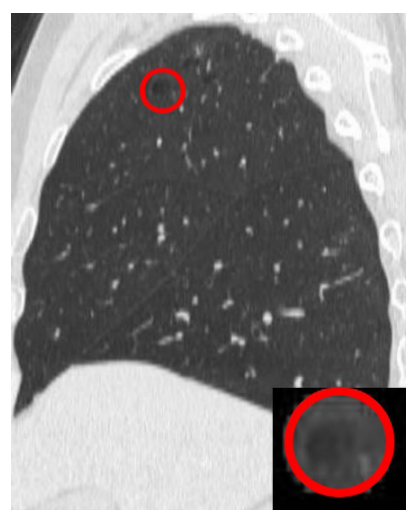

D

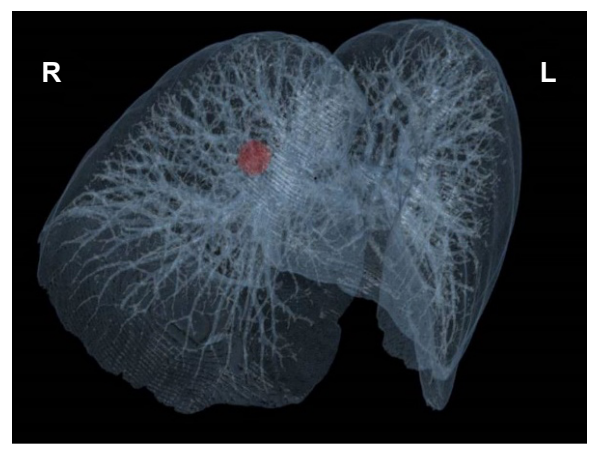

Figure I CT and 3D CT images of placement of a $2 \mathrm{~cm}$ diameter sphere in a lung.

Notes: A $2 \mathrm{~cm}$ diameter sphere appears within a red circle in the lung on transverse (A), sagittal (B), and coronal (C) planes. The placements of these three circles are finely adjusted in a synchronized manner to minimize the involvement of vessels and airways. The enhanced images of the sphere are shown in each inset. The location of the sphere (red circle) is visualized (D).

Abbreviations: 3D, three dimensional; CT, computed tomography; R, right; L, left.

diameter sphere appears as a circle in the lung on transverse (Figure 1A), sagittal (Figure 1B), and coronal (Figure 1C) planes. The placement of these three circles is finely adjusted in a synchronized manner to minimize the involvement of vessels and airways. The enhanced images of the sphere are shown in each inset. The location of the sphere is visualized on the 3D image of CT (Figure 1D).

\section{Statistical analysis}

Data were presented as mean \pm SD or as median (interquartile range). Data were compared between two groups using Student's $t$-test, Mann-Whitney $U$ test, and $\chi^{2}$ test, as appropriate. Multivariate logistic regression analyses were performed to assess factors that affected lung cancer development. Two-sided $P$-values of $<0.05$ were considered significant for all tests. Data were analyzed using JMP 10 software (SAS Institute, Cary, NC, USA).

\section{Results}

\section{Prevalence of lung cancer}

The clinical characteristics of the 435 study subjects are listed in Table 1. The mean age of the COPD patients was $72.7 \pm 8.0$ years. At baseline, $21.4 \%, 46.2 \%, 25.1 \%$, and $7.3 \%$ of the COPD patients were diagnosed with Global Initiative for
Chronic Obstructive Lung Disease grades 1, 2, 3, and 4, respectively. Figure 2 shows the prevalence of lung cancer over a 3 -year follow-up period. Lung cancer was newly diagnosed in 21 participants during the follow-up period ( $2.3 \%$ per year). Patients who dropped out from the study were older and had worse airflow limitation and lower body mass index compared to those who completed the 3-year follow-up (Table S1).

\section{Characteristics of lung cancer patients}

Table 2 shows the comparison of basic demographic characteristics between patients who developed new lung cancer

Table I Baseline characteristics of the study population

\begin{tabular}{ll}
\hline Participants (n) & 435 \\
Gender, female, $\mathrm{n}(\%)$ & $36(8.3)$ \\
Age, years & $72.7 \pm 8.0$ \\
Pack-years of smoking & $56.3 \pm 29.9$ \\
Current smokers, $\mathrm{n}(\%)$ & $46(11.0)$ \\
$\mathrm{BMI}, \mathrm{kg} / \mathrm{m}^{2}$ & $22.4 \pm 3.3$ \\
$\mathrm{FEV} / \mathrm{FVC}(\%)$ & $51.9 \pm 12.1$ \\
$\% \mathrm{FEV},(\%)$ & $61.6 \pm 21.6$ \\
COPD grades $\mathrm{I} / 2 / 3 / 4, \mathrm{n}(\%)$ & $93 / 201 / 109 / 32(21.4 / 46.2 / 25.1 / 7.3)$ \\
\hline
\end{tabular}

Note: Data are presented as $\mathrm{n}$, mean \pm standard deviation, or $\mathrm{n}(\%)$.

Abbreviations: BMI, body mass index; COPD, chronic obstructive pulmonary disease; $\mathrm{FEV}_{1}$, forced expiratory volume in I second; FVC, forced vital capacity; $\% \mathrm{FEV}_{1}$, percent predicted forced expiratory volume in I second. 
435 COPD patients confirmed by spirometry

Year 1

4 lung cancer cases $(4 / 367,1.1 \%$ person-year $)$

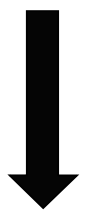

Year 2

10 lung cancer cases (10/319, 3.1\% person-year)

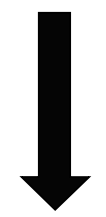

Year 3

7 lung cancer cases (7/253, 2.8\% person-year)

Figure 2 Flow chart of the study profile over 3 years of follow-up.

within 3 years and those who did not. There was no significant difference in age, pack-years of smoking, airflow limitation, and inhaled drugs between the two groups. The histologic diagnosis of lung cancer was available in 16 of 21 patients.
For the remaining five patients, lung cancer was highly suspected based on the rapid growth of tumor size on serial CT scans, assessment of the lesion by $\left[{ }^{18} \mathrm{~F}\right]$-fluoro-2-deoxy-D-glucose positron emission tomography-CT scan, and/or marked elevation of serum tumor markers. The most frequent histologic type was adenocarcinoma, followed by squamous cell carcinoma and small cell lung cancer. The patient characteristics stratified by histologic cell type are listed in Table S2.

\section{New lung cancer and emphysema}

Emphysema was observed in 129 of 240 (53.7\%) COPD patients, including $62(25.8 \%)$ mild and $67(27.9 \%)$ moderate/ severe emphysema patients. The incidence of emphysema was higher in subjects who developed lung cancer than those who did not develop lung cancer $(85.7 \%$ vs $51.8 \%, P=0.013$; Figure $3 \mathrm{~A})$. The LAA $\%$ of patients who developed lung cancer was higher than the others $(20.0 \%$ [13.1\%-27.0\%] vs $10.4 \%$ [5.0\%-20.9\%], $P=0.014$; Figure 3B). After adjusting for gender, age, and pack-year of smoking, multivariate logistic regression analysis showed an association between development lung cancer and the presence of emphysema (odds ratio [OR] 5.4, 95\% confidence interval [CI] 1.4-35.7, $P=0.012$; Table 3$)$. There was no difference between mild and moderate/ severe emphysema $(P=0.63)$, implying that the progression of emphysema did not further increase the risk for lung cancer.

\section{Lung cancer and interstitial abnormality}

Interstitial lung abnormalities were observed in 30 of 240 (12.5\%) COPD patients, including $22(9.2 \%)$ type 2 and

Table 2 Comparison of baseline characteristics between patients according to lung cancer development

\begin{tabular}{|c|c|c|c|}
\hline & $\begin{array}{l}\text { COPD patients who did } \\
\text { not develop lung cancer }\end{array}$ & $\begin{array}{l}\text { COPD patients who } \\
\text { developed lung cancer }\end{array}$ & $P$-value \\
\hline Patients, $\mathrm{n}$ & 414 & 21 & \\
\hline Gender, female, n (\%) & $34(8.2)$ & $2(9.5)$ & 0.83 \\
\hline Age, years & $72.6 \pm 8.1$ & $73.4 \pm 7.2$ & 0.65 \\
\hline Pack-years of smoking & $55.8 \pm 29.9$ & $64.4 \pm 29.6$ & 0.16 \\
\hline Current smokers, n (\%) & $45(1 \mathrm{I} .4)$ & I (4.8) & 0.62 \\
\hline Extra-pulmonary cancer, n (\%) & $77(19.4)$ & $5(23.8)$ & 0.62 \\
\hline $\mathrm{BMI}, \mathrm{kg} / \mathrm{m}^{2}$ & $22.4 \pm 3.3$ & $22.8 \pm 4.0$ & 0.69 \\
\hline $\mathrm{FEV}_{1} / \mathrm{FVC}(\%)$ & $51.8 \pm 12.1$ & $54.4 \pm 11.3$ & 0.35 \\
\hline $\mathrm{FEV}_{1}, \mathrm{~L}$ & $1.6 \pm 0.6$ & $1.7 \pm 0.5$ & 0.71 \\
\hline$\% \mathrm{FEV}_{1}(\%)$ & $61.4 \pm 21.6$ & $66.2 \pm 22.0$ & 0.25 \\
\hline \multirow[t]{2}{*}{ COPD grades I/2/3/4, n (\%) } & $86 / 193 / 104 / 31$ & $7 / 8 / 5 / 1$ & 0.57 \\
\hline & $(20.8 / 46.6 / 25.1 / 7.5)$ & $(33.3 / 38.1 / 23.8 / 4.8)$ & \\
\hline \multicolumn{4}{|l|}{ Inhaled drugs } \\
\hline ICS, n (\%) & $135(33.1)$ & $7(33.3)$ & 0.98 \\
\hline LABA, n (\%) & I8I (44.9) & $10(47.6)$ & 0.81 \\
\hline LAMA, n (\%) & $246(60.4)$ & $12(57.1)$ & 0.76 \\
\hline
\end{tabular}

Notes: Data are presented as $\mathrm{n}$, mean \pm standard deviation, or $\mathrm{n}(\%) . P$-values from chi-square test (for categorical variables) or $t$-test (for continuous variables). Abbreviations: BMI, body mass index; COPD, chronic obstructive pulmonary disease; $\mathrm{FEV}_{1}$, forced expiratory volume in I second; FVC, forced vital capacity; \%FEV , percent predicted forced expiratory volume in I second; ICS, inhaled corticosteroids; LABA, long-acting beta agonist; LAMA, long-acting muscarinic antagonist. 

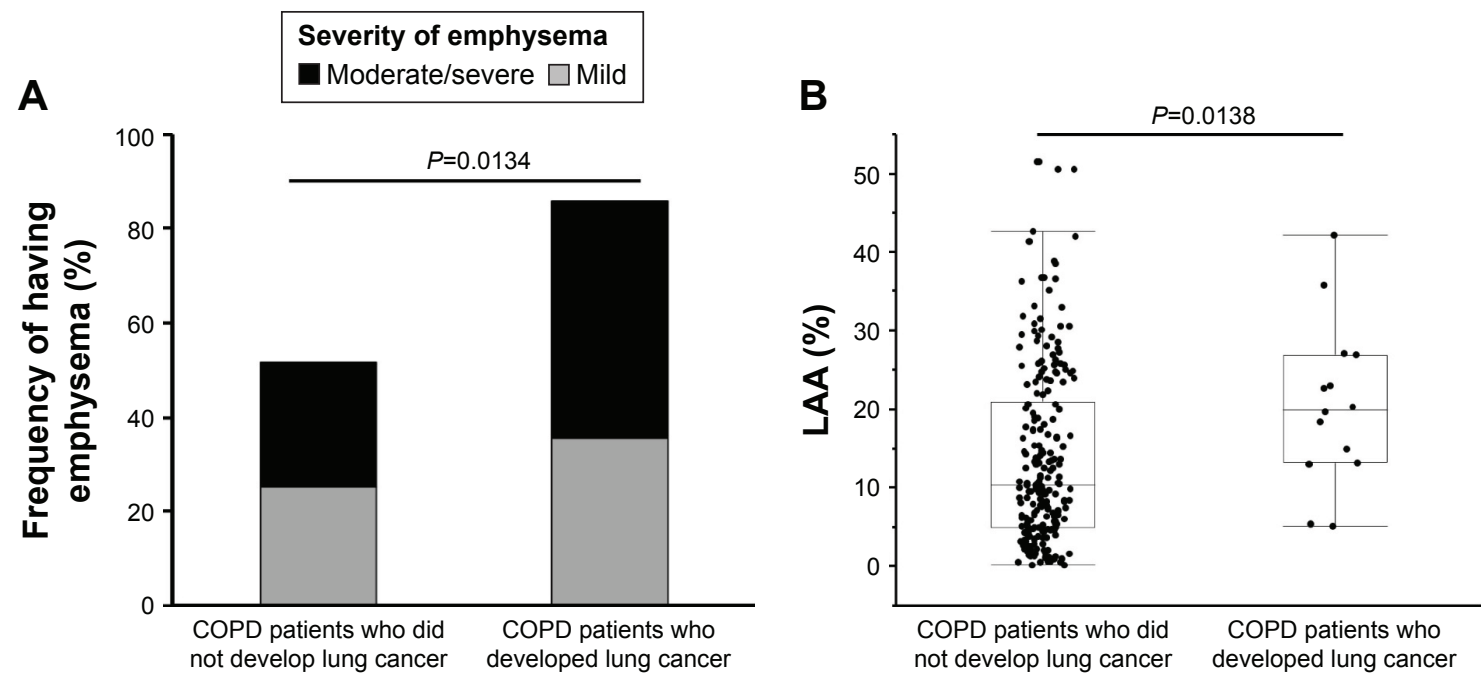

Figure 3 (A) Frequency of emphysema at enrollment between the COPD patients who developed lung cancer and those who did not. (B) LAA\% at enrollment between COPD patients who developed lung cancer afterward and those who did not. Median, 25 th and 75 th percentile values are displayed. $P$-values from chi-square tests (A) or Mann-Whitney $U$ tests (B).

Abbreviations: COPD, chronic obstructive pulmonary disease; LAA, low attenuation area.

eight (3.3\%) type 3 patients. The incidence of interstitial lung abnormalities was higher in subjects who developed lung cancer than those who did not $(64.3 \%$ vs $9.3 \%$, $P<0.0001$; Figure 4$)$. In other words, $30 \%$ of COPD patients with interstitial abnormalities (nine of 30) developed new lung cancer within 3 years. The presence of interstitial lung abnormalities was associated with the development of lung cancer (OR 17.7, 95\% CI 5.1-72.5, $P<0.0001)$. This risk was further increased when interstitial lung abnormalities were accompanied by emphysema (OR $32.2,95 \%$ CI 8.9-138.2, $P<0.0001$; Table 4). Emphysema and interstitial lung abnormalities independently raised the lung cancer risk according to multivariate logistic regression (Table S3).

\section{Histogram of CT density distribution}

As previously reported, the distribution of emphysema and interstitial abnormalities is heterogeneous and may vary

Table 3 Emphysema as a predictor of lung cancer in COPD patients

\begin{tabular}{lll}
\hline & OR (95\% Cl) & P-value \\
\hline Emphysema & & \\
Present vs none & $5.4(1.4-35.7)$ & 0.012 \\
Mild vs none & $4.6(0.9-33.3)$ & 0.063 \\
Moderate/severe vs none & $6.1(1.4-42.7)$ & 0.015 \\
Moderate/severe vs mild & $1.3(0.4-4.9)$ & 0.63 \\
\hline
\end{tabular}

Note: Analyses used multivariate logistic analysis adjusted by gender, age, and pack-years.

Abbreviations: COPD, chronic obstructive pulmonary disease; OR, odds ratio; $\mathrm{Cl}$, confidence interval. among patients. ${ }^{24,25} \mathrm{We}$ wondered whether lung cancer would likely develop in severe structural disease, relatively mild emphysematous lesions, areas of interstitial abnormalities, or even in normal-density areas. Figures 5 and 6 show two examples of chest CT findings before and after the appearance of malignant lesions, as well as the histograms of lung density distribution in each patient. The area under the curve of the histogram was considered as total lung volume. The median lung density and local spherical lung density of the precancerous site in the lung were indicated.

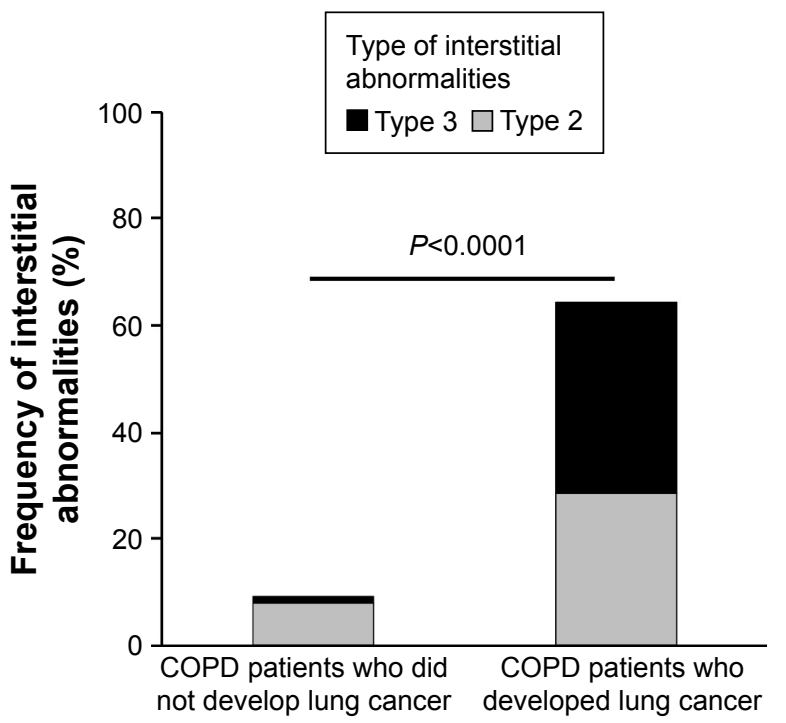

Figure 4 Frequency of interstitial abnormalities at enrollment between COPD patients who developed lung cancer and those who did not.

Note: $P$-values from chi-square test.

Abbreviation: COPD, chronic obstructive pulmonary disease. 
Table 4 Association of interstitial lung abnormality as a predictor of lung cancer in COPD patients

\begin{tabular}{lll}
\hline & OR $(95 \% \mathbf{~ C I})$ & $P$-value \\
\hline Interstitial lung abnormality & & \\
Present vs none & $17.7(5.1-72.5)$ & $<0.000$ I \\
With emphysema vs others & $32.2(8.9-138.2)$ & $<0.000$ I \\
\hline
\end{tabular}

Note: Analyses used multivariate logistic analysis adjusted by gender, age, and pack-years.

Abbreviations: COPD, chronic obstructive pulmonary disease; OR, odds ratio; $\mathrm{Cl}$, confidence interval.

Comparison of median total lung density and local spherical lung density is shown in Table 5. It should be noted that one patient (Patient ID 6) seemed to develop lung cancer in the wall of the pre-existing bullae. The histograms of the lung density in all 14 individuals are shown in Figure S1. In most COPD patients without interstitial abnormalities (four of five), the local spherical density was almost similar to the median of whole lung density distribution. On the other hand, the sphere of six of nine patients with interstitial abnormalities was located within far high attenuation area from median of whole lung density, implying interstitial abnormalities. In the remaining three patients, spherical density was almost similar to the median distribution of whole lung density.

\section{Discussion}

In this cohort, we found 21 patients newly diagnosed with lung cancer within 3 years $(2.3 \%$ per year); this is a relatively higher ratio compared to the previously reported $0.8 \%-1.7 \%$ of COPD patients developing lung cancer per year. ${ }^{26,27}$ It might be because the age of our study population was higher ${ }^{28}$ than that of other COPD clinical studies conducted in Western countries. ${ }^{26,27}$ If we could follow up patients who dropped out, the incidence of lung cancer would be even higher. When no suspicious nodular shadow was detectable, the $\mathrm{CT}$ images taken at enrollment were
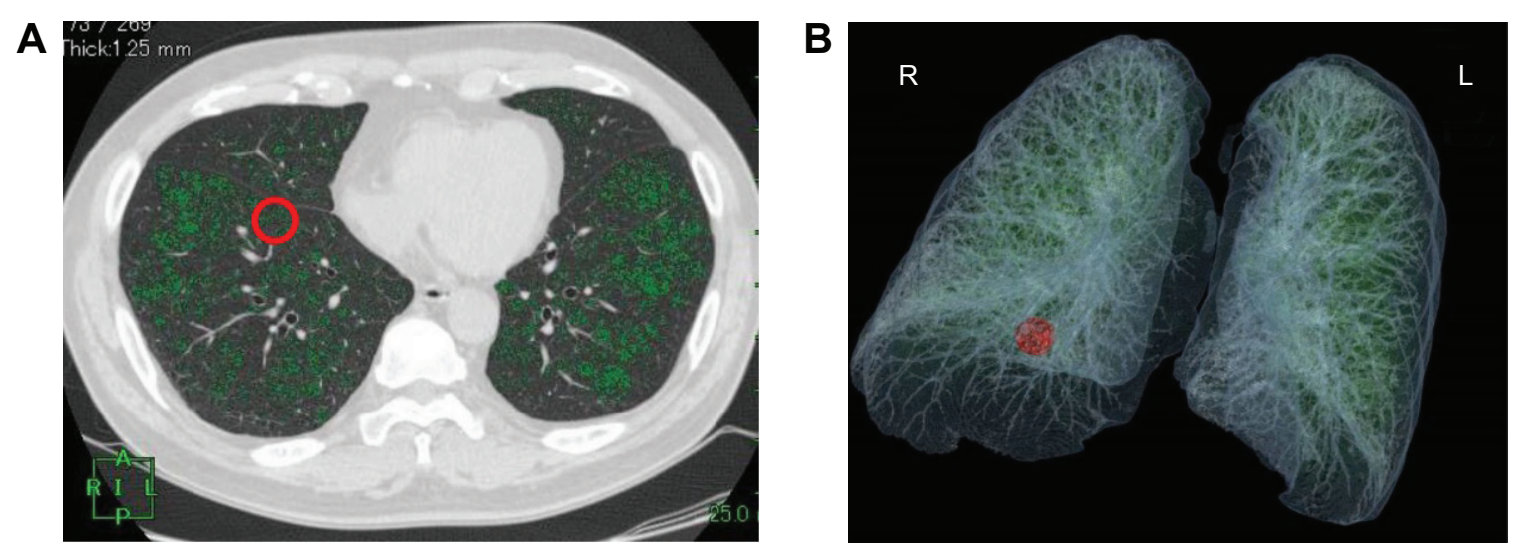

C

D
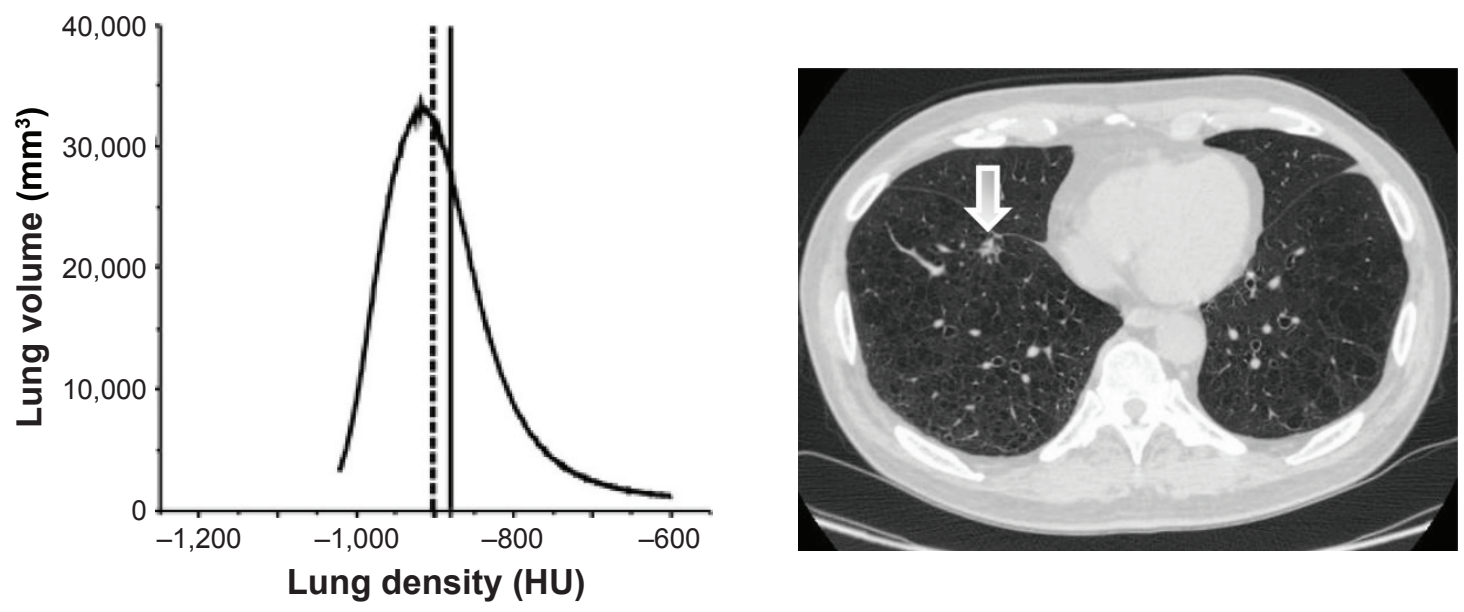

Figure 5 Chest CT scans before and after the appearance of a malignant lesion and the histogram of lung density distribution in a patient who had emphysema, but no interstitial abnormalities.

Notes: (A) A transverse CT image at enrollment with superimposed LAA (<-95 HU: green). The red circle indicates the precancerous sphere. (B) The location of the sphere is visualized on 3D CT image (red circle). (C) Histogram of CT density distribution of the entire lungs. The area under the curve of the histogram is total lung volume. The median of whole lung density is indicated as a dotted line. The solid line indicates the local lung density of precancerous sphere. (D) A transverse CT image when a suspicious lesion (arrow) was detected at the same level of $\mathbf{A}$.

Abbreviations: CT, computed tomography; LAA, low attenuation area; HU, Hounsfield unit; 3D, three dimensional; A, anterior; R, right; L, left; P, posterior. 
A

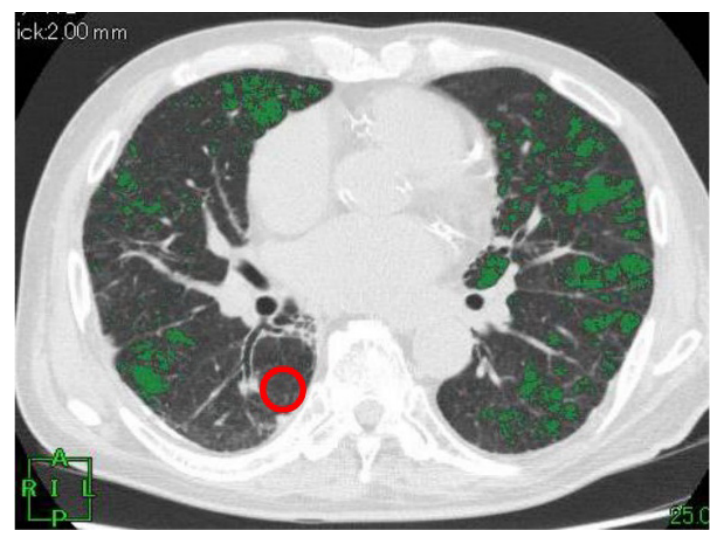

B

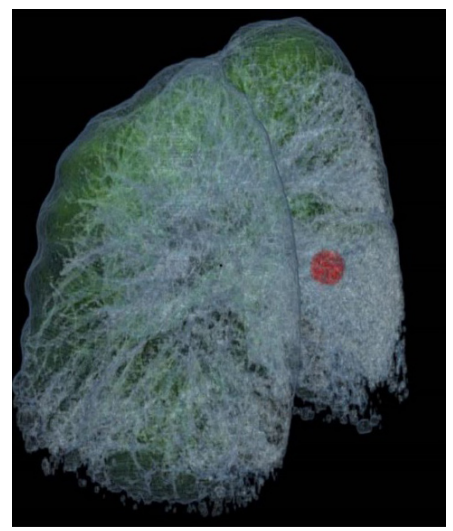

C
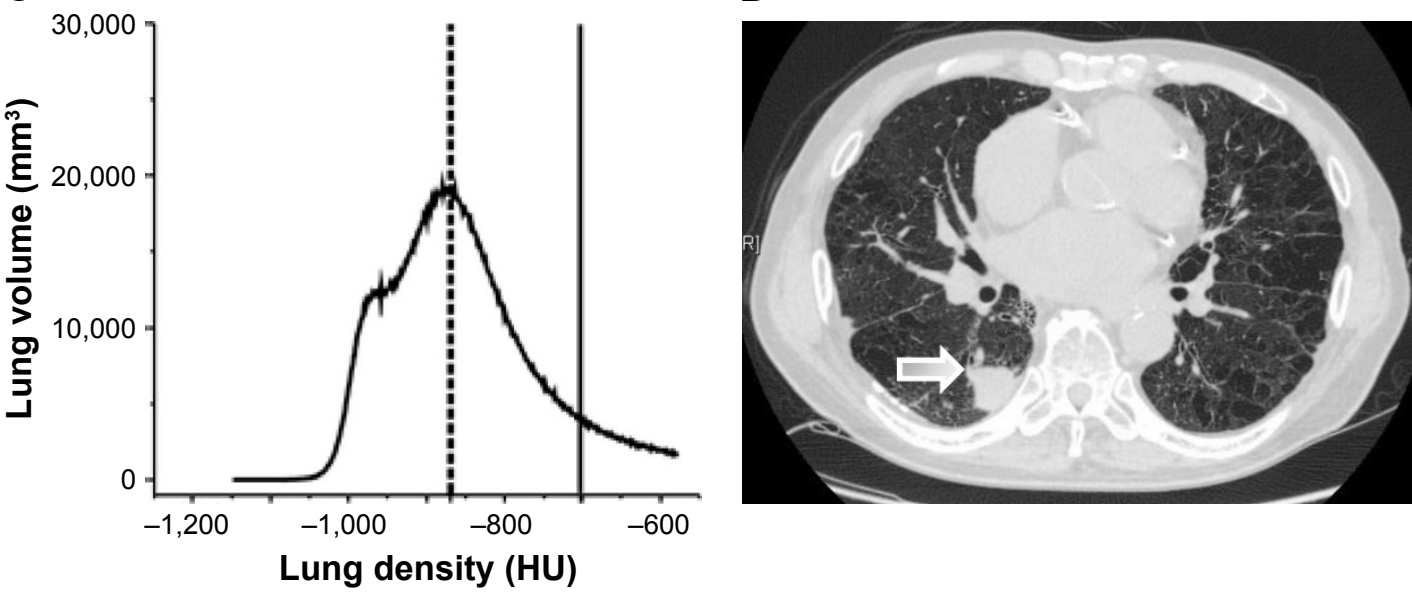

Figure 6 Chest CT scans before and after the appearance of a malignant lesion and the histogram of lung density distribution in a patient who had emphysema and interstitial abnormalities.

Notes: (A) A transverse CT image at enrollment with superimposed LAA (<-950 HU: green). The red circle indicates the precancerous sphere. (B) The location of the sphere (red circle) is visualized on 3D CT image. (C) The histogram of CT density distribution of the entire lungs. The area under the curve of the histogram is total lung volume. The median of lung attenuation is indicated as a dotted line. LAA ( $-950 \mathrm{HU})$ is shown as a shaded area. The solid line indicates the local lung density of the precancerous sphere. (D) Transverse CT image when a suspicious lesion (arrow) was detected at the same level of $\mathbf{A}$

Abbreviations: CT, computed tomography; LAA, low attenuation area; HU, Hounsfield unit; 3D, three dimensional; R, right; L, left.

Table 5 Comparison of lung densities between the whole lung and the precancerous sphere

\begin{tabular}{|c|c|c|c|c|c|c|}
\hline $\begin{array}{l}\text { Patient } \\
\text { ID }\end{array}$ & $\begin{array}{l}\text { Pathology of } \\
\text { lung cancer }\end{array}$ & $\begin{array}{l}\text { Interstitial lung } \\
\text { abnormalities }\end{array}$ & $\begin{array}{l}\text { LAA\% of } \\
\text { whole lung }\end{array}$ & $\begin{array}{l}\text { Median whole lung } \\
\text { density (HU) }\end{array}$ & $\begin{array}{l}\text { Sphere } \\
\text { density (HU) }\end{array}$ & $\begin{array}{l}\text { Difference between the } \\
\text { two densities (HU) }\end{array}$ \\
\hline I & Unknown & None & 40.0 & -932.5 & -944.0 & 11.5 \\
\hline 2 & Adeno & None & 5.9 & -898.0 & -885.2 & -12.8 \\
\hline 3 & Adeno & None & 22.1 & -902.0 & -880.8 & -21.2 \\
\hline 4 & Adeno & None & 5.3 & -858.8 & -832.7 & -26.1 \\
\hline 5 & Adeno & None & 14.9 & -896.2 & -764.4 & $-|3| .8$ \\
\hline 6 & Unknown & Present & 26.7 & -902.1 & -769.1 & -133.0 \\
\hline 7 & Small cell & Present & 34.0 & -930.9 & -674.2 & -256.7 \\
\hline 8 & Small cell & Present & 10.7 & -823.2 & -664.5 & -158.8 \\
\hline 9 & Squamous & Present & 16.1 & -868.1 & -702.4 & -165.7 \\
\hline 10 & Unknown & Present & 11.4 & -843.9 & -698.5 & -145.4 \\
\hline II & Squamous & Present & 13.8 & -904.4 & -803.8 & -100.5 \\
\hline 12 & Unknown & Present & 27.6 & -907.3 & -905.1 & -2.2 \\
\hline 13 & Adeno & Present & 19.7 & -899.9 & -910.9 & II.0 \\
\hline 14 & Squamous & Present & 17.7 & -906.9 & -901.4 & -5.5 \\
\hline
\end{tabular}

Abbreviations: LAA, low attenuation area; HU, Hounsfield unit; Adeno, adenocarcinoma; Small cell, small cell carcinoma; Squamous; squamous carcinoma. 
evaluated for characteristics of the whole lungs and further focused on the local density of the legion where lung cancer developed later.

We first demonstrated that the frequency of emphysema and LAA \% of whole lungs at enrollment were higher in subjects who developed lung cancer than in those who did not during 3 years. Taken together with the other studies, ${ }^{7-9}$ our study supported the association between emphysema and lung cancer. Our new finding was that lung cancer did not develop in severe emphysematous lesions, but it developed in non-emphysematous areas. Common mechanisms, such as chronic inflammation and oxidative stress, have been suspected in cigarette smoke-induced lung cancer and emphysema. ${ }^{29-31}$ Our finding of lung cancer development in non-emphysematous areas suggested that a different mechanism may instantaneously exist upon lung cancer development, whereas emphysema progresses in temporally and spatially heterogeneous manner for decades.

Combined pulmonary fibrosis and emphysema is a relatively new entity that is diagnosed by high-resolution CT imaging findings of the coexistence of emphysema and pulmonary fibrosis in varying extents. ${ }^{32}$ Genetic alterations, response to growth and inhibitory signals, resistance to apoptosis, myofibroblast origin and behavior, altered cellular communications, and intracellular signaling pathways are all fundamental pathogenic hallmarks of both interstitial abnormalities and cancer. ${ }^{33}$ Our data were in line with the results of several previous reports demonstrating a high prevalence of lung cancer in combined pulmonary fibrosis and emphysema patients, which appeared to be more frequent than in idiopathic pulmonary fibrosis and COPD patients. ${ }^{34-36}$ However, our local density analysis demonstrated that lung cancer developed not only in high-density areas but also in relatively normal-density areas.

The advantage of this method was that it was objective and quantitative, but the inevitable limitation is lack of pathologic assessment of the abnormality in lung density. The technical challenge is to set an arbitrarily matched spherical lesion on CT image taken at different time points from the same patient; manual fine tuning is needed to avoid existing vessels and airways, as described in Figure 1.

Our study had some limitations. First, the size of the study population that underwent digital CT analyses was relatively small. We could not follow up the patients who dropped out from this study; therefore, the incidence of lung cancer might be underestimated. This is an inherent problem of all longitudinal studies. ${ }^{37,38}$ Further studies involving larger number of nested patients and longer follow-up are necessary.

\section{Conclusion}

The presence of emphysema, interstitial abnormalities, and both are significant risk factors for future lung cancer development in COPD patients. Furthermore, lung cancer likely develops in non-emphysematous areas or in interstitial abnormalities, if any, but not in emphysematous lesions. Our findings might help identify imaging-based measurements of risk, detection, subtype, and progression of lung cancer in COPD patients.

\section{Acknowledgments}

The authors acknowledge Masahiro Jinzaki of the Department of Diagnostic Radiology, Keio University School of Medicine, and Tamami Nakajima of AZE for helping in the analysis of chest CT imaging findings and in calibrating the CT instruments; Chiyomi Uemura for helping with data collection; and Hidehiro Irie for helping with data collection and interpretation of data. The authors also acknowledge all the members of the Keio COPD Comorbidity Research Group who participated in this study, including Saiseikai Utsunomiya Hospital, Eiju General Hospital, Tokyo Saiseikai Central Hospital, Sano Public Welfare General Hospital, Nihon Kokan Hospital, Saitama Social Insurance Hospital, Kawasaki City Ida Hospital, Saitama City Hospital, Tokyo Medical Center, Tokyo Dental College Ichikawa General Hospital, Tokyo Electric Power Company Hospital, and the International Medical Welfare College Shioya Hospital.

\section{Author contributions}

Shotaro Chubachi participated in the design of the study, performed the statistical analyses, and was a major contributor in writing the manuscript. Tomoko Betsuyaku planned the study design and contributed to interpretation of results. Hidetoshi Nakamura, Koichiro Asano, and Tomoko Betsuyaku conceived the study, participated in its design and coordination, and helped to draft the manuscript. Saeko Takahashi, Akihiro Tsutsumi, Naofumi Kameyama, Mamoru Sasaki, Katsuhiko Naoki, and Kenzo Soejima contributed to collection of data, interpretation of results, and helped to draft the manuscript. All authors read and approved the final manuscript and agree to be accountable for all aspects of the work.

\section{Disclosure}

The authors report no conflicts of interest in this work.

\section{References}

1. Chatila WM, Thomashow BM, Minai OA, Criner GJ, Make BJ. Comorbidities in chronic obstructive pulmonary disease. Proc Am Thorac Soc. 2008;5(4):549-555. 
2. Sin DD, Anthonisen NR, Soriano JB, Agusti AG. Mortality in COPD: role of comorbidities. Eur Respir J. 2006;28(6):1245-1257.

3. Hackshaw AK, Law MR, Wald NJ. The accumulated evidence on lung cancer and environmental tobacco smoke. BMJ. 1997;315(7114) 980-988.

4. Tockman MS, Anthonisen NR, Wright EC, Donithan MG. Airways obstruction and the risk for lung cancer. Ann Intern Med. 1987;106(4): 512-518.

5. Spira A, Halmos B, Powell CA. Update in lung cancer 2015. Am J Respir Crit Care Med. 2016;194(6):661-671.

6. Wasswa-Kintu S, Gan WQ, Man SF, Pare PD, Sin DD. Relationship between reduced forced expiratory volume in one second and the risk of lung cancer: a systematic review and meta-analysis. Thorax. 2005; 60(7):570-575.

7. Zulueta JJ, Wisnivesky JP, Henschke CI, et al. Emphysema scores predict death from COPD and lung cancer. Chest. 2012;141(5):1216-1223.

8. de Torres JP, Bastarrika G, Wisnivesky JP, et al. Assessing the relationship between lung cancer risk and emphysema detected on low-dose CT of the chest. Chest. 2007;132(6):1932-1938.

9. Wilson DO, Weissfeld JL, Balkan A, et al. Association of radiographic emphysema and airflow obstruction with lung cancer. Am J Respir Crit Care Med. 2008;178(7):738-744.

10. Pipavath SN, Schmidt RA, Takasugi JE, Godwin JD. Chronic obstructive pulmonary disease: radiology-pathology correlation. $J$ Thorac Imaging. 2009;24(3):171-180.

11. Washko GR, Hunninghake GM, Fernandez IE, et al. Lung volumes and emphysema in smokers with interstitial lung abnormalities. $N$ Engl $J$ Med. 2011;364(10):897-906.

12. Mizuno S, Takiguchi Y, Fujikawa A, et al. Chronic obstructive pulmonary disease and interstitial lung disease in patients with lung cancer. Respirology. 2009;14(3):377-383.

13. Loganathan RS, Stover DE, Shi W, Venkatraman E. Prevalence of COPD in women compared to men around the time of diagnosis of primary lung cancer. Chest. 2006;129(5):1305-1312.

14. Lee YR, Choi YW, Lee KJ, Jeon SC, Park CK, Heo JN. CT halo sign: the spectrum of pulmonary diseases. Br J Radiol. 2005;78(933): 862-865.

15. Dilger SK, Uthoff J, Judisch A, et al. Improved pulmonary nodule classification utilizing quantitative lung parenchyma features. $J$ Med Imaging (Bellingham). 2015;2(4):041004.

16. Sekine A, Tamura K, Satoh H, et al. Prevalence of underlying lung disease in smokers with epidermal growth factor receptor-mutant lung cancer. Oncol Rep. 2013;29(5):2005-2010.

17. Miyazaki M, Nakamura H, Chubachi S, et al. Analysis of comorbid factors that increase the COPD assessment test scores. Respir Res. 2014;15:13.

18. Chubachi S, Sato M, Kameyama N, et al. Identification of five clusters of comorbidities in a longitudinal Japanese chronic obstructive pulmonary disease cohort. Respir Med. 2016;117:272-279.

19. Sato M, Chubachi S, Sasaki M, et al. Impact of mild exacerbation on COPD symptoms in a Japanese cohort. Int J Chron Obstruct Pulmon Dis. 2016;11:1269-1278.

20. Miyazaki M, Nakamura H, Takahashi S, et al. The reasons for triple therapy in stable COPD patients in Japanese clinical practice. Int $J$ Chron Obstruct Pulmon Dis. 2015;10:1053-1059.
21. Miller MR, Hankinson J, Brusasco V, et al. Standardisation of spirometry. Eur Respir J. 2005;26(2):319-338.

22. Nishimura M, Aizawa H, Kanbe M, et al. Committee of Pulmonary Physiology, the Japanese Respiratory Society Guidelines for Pulmonary Function Tests: Spirometry, Flow-volume Curve, Diffusion Capacity of the Lung. Tokyo: Japanese Respiratory Society; 2004:20-23.

23. Chubachi S, Nakamura H, Sasaki M, et al. Polymorphism of LRP5 gene and emphysema severity are associated with osteoporosis in Japanese patients with or at risk for COPD. Respirology. 2015;20(2):286-295.

24. Washko GR, Lynch DA, Matsuoka S, et al. Identification of early interstitial lung disease in smokers from the COPDGene Study. Acad Radiol. 2010;17(1):48-53.

25. Smith BM, Austin JH, Newell JD Jr, et al. Pulmonary emphysema subtypes on computed tomography: the MESA COPD Study. Am J Med. 2014;127(1):94.e7-94.e23.

26. Skillrud DM, Offord KP, Miller RD. Higher risk of lung cancer in chronic obstructive pulmonary disease. A prospective, matched, controlled study. Ann Intern Med. 1986;105(4):503-507.

27. de Torres JP, Marin JM, Casanova C, et al. Lung cancer in patients with chronic obstructive pulmonary disease - incidence and predicting factors. Am J Respir Crit Care Med. 2011;184(8):913-919.

28. Haraguchi M, Nakamura H, Sasaki M, et al. Determinants of chronic obstructive pulmonary disease severity in the late-elderly differ from those in younger patients. BMC Res Notes. 2016;9:7.

29. Houghton AM, Mouded M, Shapiro SD. Common origins of lung cancer and COPD. Nat Med. 2008;14(10):1023-1024.

30. Adcock IM, Caramori G, Barnes PJ. Chronic obstructive pulmonary disease and lung cancer: new molecular insights. Respiration. 2011; 81(4):265-284.

31. Caramori G, Casolari P, Cavallesco GN, Giuffre S, Adcock I, Papi A. Mechanisms involved in lung cancer development in COPD. Int $J$ Biochem Cell Biol. 2011;43(7):1030-1044.

32. Papaioannou AI, Kostikas K, Manali ED, et al. Combined pulmonary fibrosis and emphysema: the many aspects of a cohabitation contract. Respir Med. 2016;117:14-26.

33. Vancheri C, Failla M, Crimi N, Raghu G. Idiopathic pulmonary fibrosis: a disease with similarities and links to cancer biology. Eur Respir J. 2010;35(3):496-504.

34. Kurashima K, Takayanagi N, Tsuchiya N, et al. The effect of emphysema on lung function and survival in patients with idiopathic pulmonary fibrosis. Respirology. 2010;15(5):843-848.

35. Kitaguchi Y, Fujimoto K, Hanaoka M, Kawakami S, Honda T, Kubo K. Clinical characteristics of combined pulmonary fibrosis and emphysema. Respirology. 2010;15(2):265-271.

36. Kwak N, Park CM, Lee J, et al. Lung cancer risk among patients with combined pulmonary fibrosis and emphysema. Respir Med. 2014; 108(3):524-530.

37. Vestbo J, Anderson JA, Calverley PM, et al. Bias due to withdrawal in long-term randomised trials in COPD: evidence from the TORCH study. Clin Respir J. 2011;5(1):44-49.

38. Coxson HO, Dirksen A, Edwards LD, et al. The presence and progression of emphysema in COPD as determined by CT scanning and biomarker expression: a prospective analysis from the ECLIPSE study. Lancet Respir Med. 2013;1(2):129-136. 


\section{Supplementary materials}

Table SI Comparison of baseline characteristics between patients with 3-year follow-up and those who dropped out

\begin{tabular}{llll}
\hline & $\begin{array}{l}\text { Patients with } \\
\text { 3-year follow-up }\end{array}$ & $\begin{array}{l}\text { Patients who } \\
\text { dropped out }\end{array}$ & P-value \\
\hline Patients, n & 253 & 182 & $19(10.4)$ \\
Gender, female, n (\%) & $17(6.7)$ & $74.0 \pm 8.4$ & 0.16 \\
Age, years & $71.8 \pm 7.6$ & $55.3 \pm 28.7$ & 0.0046 \\
Pack-years of smoking & $56.9 \pm 30.8$ & $21.7 \pm 3.6$ & 0.60 \\
BMl, kg/m & $22.9 \pm 3.0$ & $50.8 \pm 12.1$ & 0.00020 \\
FEV $/$ FVC (\%) & $52.7 \pm 12.0$ & $58.7 \pm 22.6$ & 0.11 \\
\%FEV & $63.7 \pm 20.7$ & 0.018 \\
\hline
\end{tabular}

Notes: Data are presented as $\mathrm{n}$, mean $\pm \mathrm{SD}$, or $\mathrm{n}(\%)$. P-values from chi-square test (for categorical variables) or $t$-test (for continuous variables).

Abbreviations: BMI, body mass index; $\mathrm{FEV}_{1}$, forced expiratory volume in I second; FVC, forced vital capacity; \% $\mathrm{FEV}_{1}$, percent predicted forced expiratory volume in I second; SD, standard deviation.

Table S2 Comparison of baseline characteristics according to pathology of lung cancer

\begin{tabular}{|c|c|c|c|c|}
\hline & Adenocarcinoma & $\begin{array}{l}\text { Squamous cell } \\
\text { carcinoma }\end{array}$ & $\begin{array}{l}\text { Small cell } \\
\text { carcinoma }\end{array}$ & Undiagnosed \\
\hline Patients, $\mathrm{n}$ & 9 & 4 & 3 & 5 \\
\hline Gender, female, n (\%) & I (II.I) & $0(0)$ & I (33.3) & $0(0)$ \\
\hline Age, years & $70.8 \pm 8.4$ & $76.5 \pm 6.2$ & $72.0 \pm 7.5$ & $76.6 \pm 4.6$ \\
\hline Smoking index, pack-years & $61.6 \pm 20.0$ & $65.9 \pm 28.5$ & $48.2 \pm 14.0$ & $78.1 \pm 49.2$ \\
\hline Current smokers, n (\%) & $0(0)$ & I $(25.0)$ & $0(0)$ & $0(0)$ \\
\hline Previous history of extra-pulmonary cancer, $\mathrm{n}(\%)$ & I (II.I) & I (25.0) & I (33.3) & $2(40.0)$ \\
\hline$\% \mathrm{FEV}_{1}$ & $73.9 \pm 19.4$ & $49.1 \pm 19.4$ & $64.8 \pm 25.7$ & $66.9 \pm 25.1$ \\
\hline COPD grades $I / 2 / 3 / 4, n$ & $4 / 3 / 2 / 0$ & $0 / 3 / 0 / 1$ & $\mathrm{I} / \mathrm{I} / \mathrm{I} / 0$ & $2 / 1 / 2 / 0$ \\
\hline \multicolumn{5}{|l|}{ Blood examination } \\
\hline Leukocytes, $\times 10^{9} / \mathrm{L}$ & $7.3 \pm 1.6$ & $6.8 \pm 2.1$ & $9.2 \pm 0.3$ & $6.4 \pm 0.7$ \\
\hline $\mathrm{CRP}, \mathrm{mg} / \mathrm{dL}$ & $0.4 \pm 0.3$ & $0.6 \pm 0.8$ & $0.5 \pm 0.5$ & $0.1 \pm 0.1$ \\
\hline $\mathrm{SAA} / \mu \mathrm{g} / \mathrm{mL}$ & $12.0 \pm 11.1$ & $16.3 \pm 12.4$ & $33.4 \pm 23.8$ & $75.6 \pm 129.1$ \\
\hline $\mathrm{CEA} / \mathrm{ng} / \mathrm{mL}$ & $28.3 \pm 57.6$ & $4.1 \pm 0.8$ & $4.4 \pm 0.4$ & $5.3 \pm 3.5$ \\
\hline Pro-GRP/pg/mL & $45.5 \pm 9.9$ & $51.8 \pm 19.2$ & $73.4 \pm 7.3$ & $102.7 \pm 32.7$ \\
\hline CYFRA/ng/mL & $2.2 \pm 1.4$ & $2.5 \pm 2.0$ & $3.2 \pm 2.3$ & $3.9 \pm 2.8$ \\
\hline \multicolumn{5}{|l|}{ Clinical stage of NSCLC } \\
\hline I/II/III/IV/unknown, n & $6 / 0 / 2 / 1 / 0$ & $1 / 1 / 1 / 1 / 0$ & & $3 / 0 / 0 / 0 / 2$ \\
\hline Clinical stage of SCLC LD/ED & & & $\mathrm{I} / 2$ & \\
\hline \multicolumn{5}{|l|}{ Location of primary mass } \\
\hline Upper/middle/lower lobes, $\mathrm{n}$ & $6 / 0 / 3$ & $1 / 0 / 3$ & $0 / 1 / 2$ & $1 / 2 / 2$ \\
\hline \multicolumn{5}{|l|}{ Diagnosis and annual follow-up } \\
\hline Chest CT/other extra causes, $\mathrm{n}$ & $8 / 1$ & $4 / 0$ & $\mathrm{I} / 2$ & $4 / 1$ \\
\hline \multicolumn{5}{|l|}{ Treatment } \\
\hline $\begin{array}{l}\text { Operation/radiation/chemotherapy + radiation/ } \\
\text { chemotherapy/best supportive care, } n\end{array}$ & $5 / 0 / 1 / 2 / 1$ & $0 / 1 / 0 / 2 / 1$ & $0 / 0 / 0 / 3 / 0$ & $0 / 1 / 0 / 0 / 4$ \\
\hline
\end{tabular}

Note: Data are presented as $n$, mean \pm SD, or $n(\%)$.

Abbreviations: \%FEV , percent predicted forced expiratory volume in I second; COPD, chronic obstructive pulmonary disease; CRP, C-reactive protein; SAA, serum amyloid A; CEA, carcinoembryonic antigen; pro-GRP, pro-gastrin-releasing peptide; CYFRA, cytokeratin-19 fragments; NSCLC, non-small cell lung cancer; SCLC, small cell lung cancer; LD, limited disease; ED, extensive disease; CT, computed tomography; SD, standard deviation.

Table S3 Emphysema and interstitial lung abnormalities as an independent risk factor for future lung cancer in COPD patients

\begin{tabular}{lll}
\hline & OR $(95 \% \mathbf{C l})$ & $P$-value \\
\hline Emphysema & $4.2(1.0-29.0)$ & 0.049 \\
$\quad \begin{array}{l}\text { Present vs none } \\
\text { Interstitial lung abnormality } \\
\text { Present vs none }\end{array}$ & $15.6(4.4-65.4)$ & $<0.0001$ \\
\hline
\end{tabular}

Note: Multivariate logistic analysis adjusted by gender, age, and pack-years.

Abbreviations: COPD, chronic obstructive pulmonary disease; $\mathrm{OR}$, odds ratio; $\mathrm{Cl}$, confidence interval. 

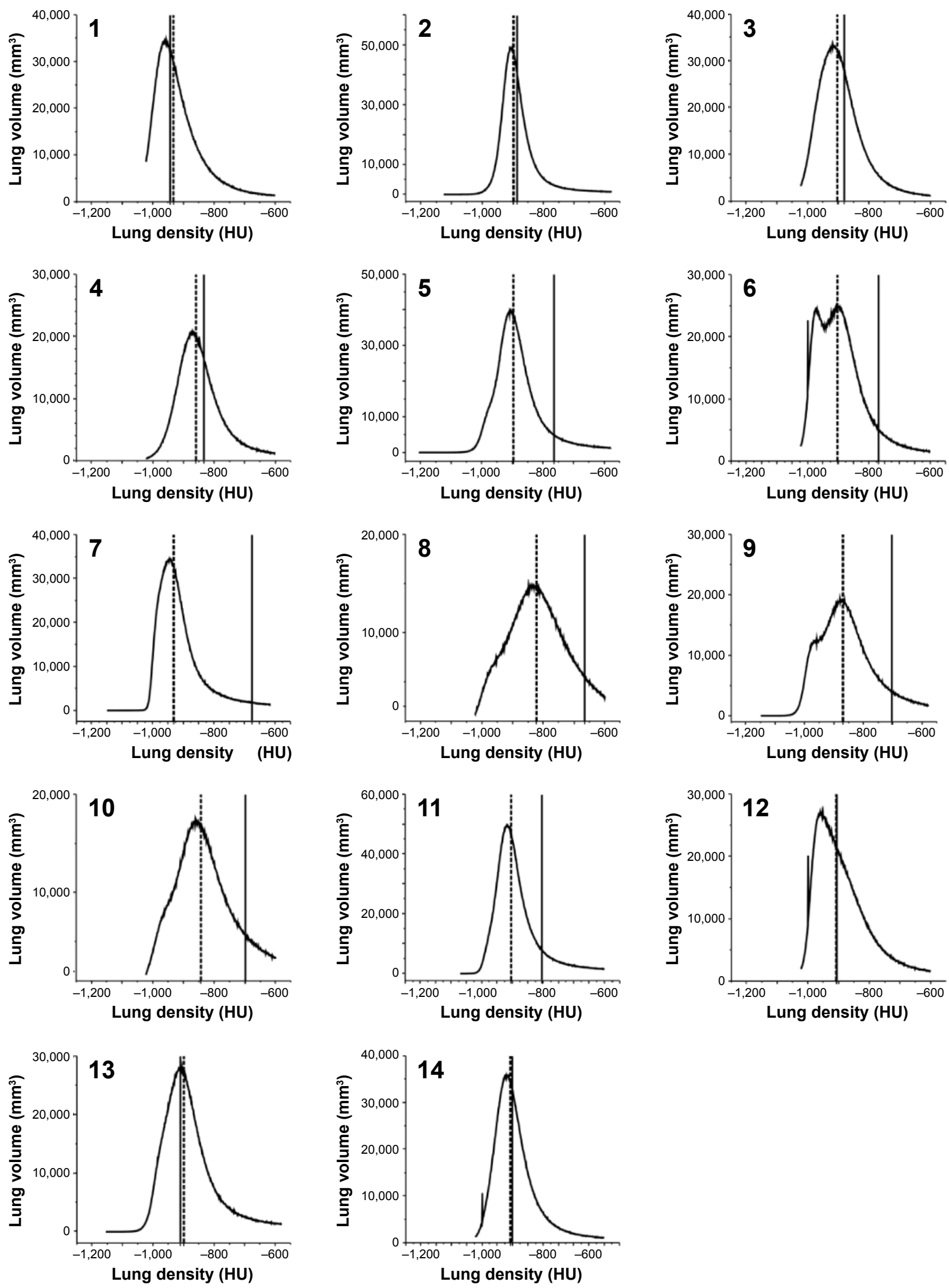

Figure SI The histograms of the lung density of all 14 individuals.

Notes: There are five individuals without interstitial lung abnormalities (ID I-5) and nine individuals with interstitial lung abnormalities (ID 6-I4). The area under the curve of the histogram is total lung volume. The median of lung attenuation is indicated as a dotted line. The solid line indicates the local lung density of the precancerous sphere. Abbreviation: HU, Hounsfield unit. 


\section{Publish your work in this journal}

The International Journal of COPD is an international, peer-reviewed journal of therapeutics and pharmacology focusing on concise rapid reporting of clinical studies and reviews in COPD. Special focus is given to the pathophysiological processes underlying the disease, intervention programs, patient focused education, and self management protocols.

This journal is indexed on PubMed Central, MedLine and CAS. The manuscript management system is completely online and includes a very quick and fair peer-review system, which is all easy to use. Visit http://www.dovepress.com/testimonials.php to read real quotes from published authors. 